\title{
Which Primary Organ Is Most Suitable for Performing Pulmonary Metastasectomy?
}

\author{
FUMIHIKO HIRAI ${ }^{1}$, IKUHIKO KINOSHITA $^{1}$, TAICHI MATSUBARA ${ }^{1}$, NAOKI HARATAKE ${ }^{1}$, \\ YUKA KOUZUMA ${ }^{1}$, SHINKICHI TAKAMORI ${ }^{1}$, TAKAI AKAMINE ${ }^{1}$, GOUJI TOYOKAWA ${ }^{1}$, \\ TETSUZO TAGAWA $^{1}$, MITSUHIRO TAKENOYAMA ${ }^{2}$ and YOSHIHIKO MAEHARA ${ }^{1}$ \\ ${ }^{1}$ Department of Surgery and Science, Graduate School of Medical Sciences, Kyushu University, Fukuoka, Japan; \\ ${ }^{2}$ Department of Thoracic Oncology, National Kyushu Cancer Center, Fukuoka, Japan
}

\begin{abstract}
Background/Aim: The aim of this study was to assess the appropriateness of pulmonary metastasectomy (MT), with a focus on the primary organ. Patients and Methods: The pathological status of the primary organ, outcome of the MT, disease-free interval, and overall survival were assessed. Results: The primary organ was the most significant prognostic factor analyzed, with a relative risk of 4.6 (95\% confidence interval: 1.69-12.56, $p=0.003)$. Patients with colorectal carcinoma had a better survival than those with another primary organ $(p=0.003)$. The hazard ratios by primary organ in comparison to colorectal carcinoma were 3.2 for head and neck carcinoma, 3.5 for soft tissue sarcoma, 8.3 for hepatocellular carcinoma, and 8.9 for urinary carcinoma. Conclusion: Colorectal carcinoma is associated with a greater survival benefit than cancer of other primary organs. Colorectal carcinoma cases should be more aggressively considered for MT than other primary organ cases.
\end{abstract}

No randomized prospective trials have compared surgical therapy to medical therapy or observation, and resection of pulmonary metastases (PMs) has been considered in select patients. Surgical resection of PMs may prolong the survival of certain patients. However, while resection might be the better survival option for some patients with PMs, the influential factors and methods of patient selection remain controversial.

Colorectal carcinoma is the most common primary organ of malignant solid tumor (MST) for patients with potentially resectable PMs. Many studies have suggested a survival

Correspondence to: Fumihiko Hirai, Department of Surgery and Science, Graduate School of Medical Sciences, Kyushu University, 3-1-1 Maedashi, Higashi-ku, Fukuoka 812-8582, Japan. Tel: +81 926425466, Fax: +81 926425482, e-mail: fhirai@surg2.med.kyushuu.ac.jp

Key Words: Pulmonary metastases, malignant solid tumor, metastasectomy, prognostic factor. benefit in select patients if complete resection of PMs is accomplished (1-4). Several retrospective studies have shown that patients with isolated PMs from colorectal carcinoma benefit from MT. The expected 5-year survival after surgical resection of PMs is $30-68 \%(5,6)$. Several studies have analyzed the prognostic factors of MT, but the criteria for PMs are unclear due to differences in various study findings (7-9).

Also unclear is whether or not MT may play a role in the multidisciplinary management of other MSTs, such as those from primary gastric cancer, urinary tract cancer, breast cancer, hepatocellular carcinoma, and gynecologic cancer. Several studies have reported that MT should be considered in certain patients with PMs from MST other than colorectal cancer (1012). However, MT has no role in the standard management of MST patients and may actually be proposed only in certain highly select cases. Furthermore, the efficacy of systemic chemotherapy for several MSTs has improved, and various molecular-targeted agents have been introduced. The treatment options for MST with PMs are therefore increasing.

At present, patient selection for MT of various primary organs is based mostly on empirical studies, which often report the experience of a single institution. As such, the risk factors for a prolonged survival are poorly defined, and the actual benefits of surgery in this setting remain controversial in the recent era of standard chemotherapy. Although, several retrospective studies have shown that patients with PMs from MST benefit from MT, there were few reports of comparing the survival benefit of MT in same institution.

In the present study, we evaluated the survival after resection for patients with PMs from MST and assessed the appropriateness of MT, with a focus on the primary organ.

\section{Patients and Methods}

Patients. Between January 2000 and December 2015, 106 patients underwent MT for MST at one institution. The inclusion criteria were as follows: (1) control of the primary tumor or the ability to resect 
the primary tumor completely simultaneously with resection of metastases; (2) the ability to resect the metastatic disease completely; (3) extrathoracic metastases controlled or resected. There were no limitations set for the tumor number or size, as long as the tumor was considered to be resectable under the criteria above. Surgery was performed as limited resection (i.e. wedge resection, segmentectomy) for pulmonary nodules, but we performed lobectomy when the tumor was centrally located, when the tumor was larger than $3 \mathrm{~cm}$, or when the tumor was indistinguishable from primary lung cancer. Lymph node sampling was performed when the hilar or mediastinal lymph nodes were swollen, but systematic lymph node dissection was performed only when primary lung cancer could not be ruled out.

Statistical analyses. All patients were retrospectively analyzed for age, gender, the primary organ and the information of PMs (i.e. size, number and site of pulmonary lob). The event used for the assessment of efficiency was death. The median follow-up period was 997 days (range $=7-2316$ days). The disease-free interval (DFI) was considered to be the period between surgery and the date of the recurrence, and the overall survival (OS) was considered to be the period between surgery and the date of the last follow-up or death. These rates were estimated using the Kaplan-Meier method with the log-rank test. The Cox model was used for the multivariate analysis of prognostic factors for survival. The factors analyzed included the gender, size of PMs, number of PMs, site of PMs, surgical procedure, primary organ, the presence of chemotherapy after MT. All statistical analyses were performed using the Stat View software program, version 5.0 (SAS Institute, Cary, NC, USA). All results were considered statistically significant for $p<0.05$. Follow-up concluded on November 30, 2016.

\section{Results}

Patient characteristics. Table I summarizes the background characteristics of all patients who received MT in this study. There were 58 males and 48 females, with a median age of 66 years (range $=14-83$ years). The Eastern Cooperative Oncology Group performance status (PS) was 0 in 85 cases, 1 in 20 cases, and 2 in 1 case. The type of primary organ was colorectal carcinoma in 43 cases, soft tissue sarcoma in 14 cases, urinary tract carcinoma in 12 cases, esophageal/gastric carcinoma in 10 cases, head and neck carcinoma 10 cases, gynecologic carcinoma in 8 cases, breast carcinoma in 6 cases, and hepatocellular carcinoma in 3 cases. The number of PMs was 1 in 78 cases, 2 in 14 cases, 3 in 7 cases, 4 in 2 cases, and $\geq 5$ in 5 cases. The median time to metastasectomy from the primary organ operation was 53 months (range $=0-240$ months). The site of pulmonary metastasis was unilateral in 87 cases and bilateral in 19 cases. The surgical procedure was partial resection in 70 cases, segmentectomy in 13 cases, and lobectomy in 23 cases. Of the 106 patients, 38 received postmetastasectomy chemotherapy.

The DFI and OS. The median DFI and OS after the first MT were 23.4 months and "not reached", respectively (Figure 1). A good prolonged OS was noted for colorectal carcinoma (median OS: 63.0 months). In contrast, a poor prognosis was noted for hepatocellular carcinoma (median OS: 10.3 months).
Table I. Patient characteristics.

\begin{tabular}{|c|c|}
\hline Character & $\begin{array}{c}\text { Number of patients } \\
n=106\end{array}$ \\
\hline \multicolumn{2}{|l|}{ Gender } \\
\hline Male & 58 \\
\hline Female & 48 \\
\hline \multicolumn{2}{|l|}{ Age } \\
\hline Median (range, years) & $66(14-83)$ \\
\hline \multicolumn{2}{|l|}{ ECOG performance status } \\
\hline $0 / 1 / 2$ & $85 / 20 / 1$ \\
\hline \multicolumn{2}{|l|}{ Smoking status } \\
\hline Current/Former & 50 \\
\hline Never & 56 \\
\hline \multicolumn{2}{|l|}{ Primary organ } \\
\hline Colorectal & 43 \\
\hline Soft tissue sarcoma & 14 \\
\hline Urinary tract & 12 \\
\hline Esophageal/gastric & 10 \\
\hline Head and neck & 10 \\
\hline Gynecologic & 8 \\
\hline Breast & 6 \\
\hline Hepatocellular carcinoma & 3 \\
\hline \multicolumn{2}{|l|}{ Number of PMs } \\
\hline $1 / 2 / 3 / 4 / \geq 5$ & $78 / 14 / 7 / 2 / 5$ \\
\hline \multicolumn{2}{|l|}{ Size of PM } \\
\hline$\leq 3 \mathrm{~cm}$ & 93 \\
\hline$>3 \mathrm{~cm}$ & 13 \\
\hline \multicolumn{2}{|l|}{ Site of PM } \\
\hline Unilateral/bilateral & $87 / 19$ \\
\hline \multicolumn{2}{|c|}{ Time to MT from primary operation } \\
\hline Median (range, months) & $53(0-240)$ \\
\hline \multicolumn{2}{|l|}{ Surgical procedure } \\
\hline Partial resection & 70 \\
\hline Segmentectomy & 13 \\
\hline Lobectomy & 23 \\
\hline \multicolumn{2}{|l|}{ Chemotherapy after MT } \\
\hline Yes/No & $38 / 68$ \\
\hline
\end{tabular}

ECOG: Eastern Cooperative Oncology Group; PM: pulmonary metastasis; MT: metastasectomy.

Univariate and multivariate analyses of the prognostic factors for the survival. Univariate and multivariate analyses were performed to identify the independent factors predicting the survival using a Cox proportional hazards model (Table II). Among the factors analyzed, the primary organ was the most significant prognostic factor, with a relative risk of 4.6 (95\% confidence interval $=1.69-12.56, p=0.003$ ).

OS according to the primary organ. Patients with colorectal carcinoma had a better survival than those with other primary organs ( $p=0.003$, Figure 2 ). The hazard ratio by primary organ was 1.9 for esophageal/gastric carcinoma, 2.7 for gynecologic carcinoma, 3.0 for breast carcinoma, 3.2 for head and neck carcinoma, 3.5 for soft tissue sarcoma, 8.3 for hepatocellular carcinoma, and 8.9 for urinary carcinoma (Table III). 
A

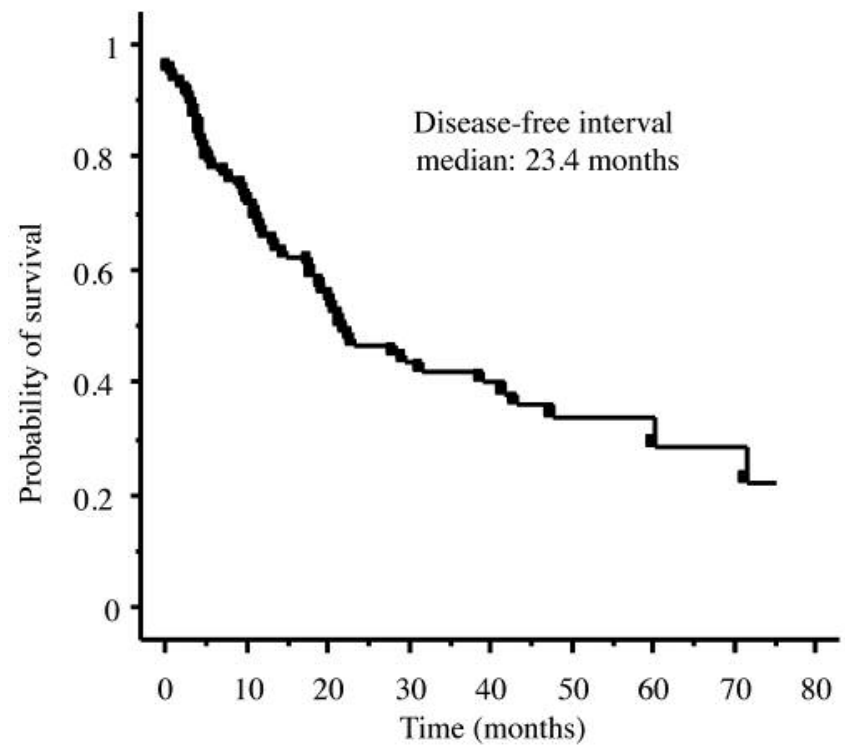

B

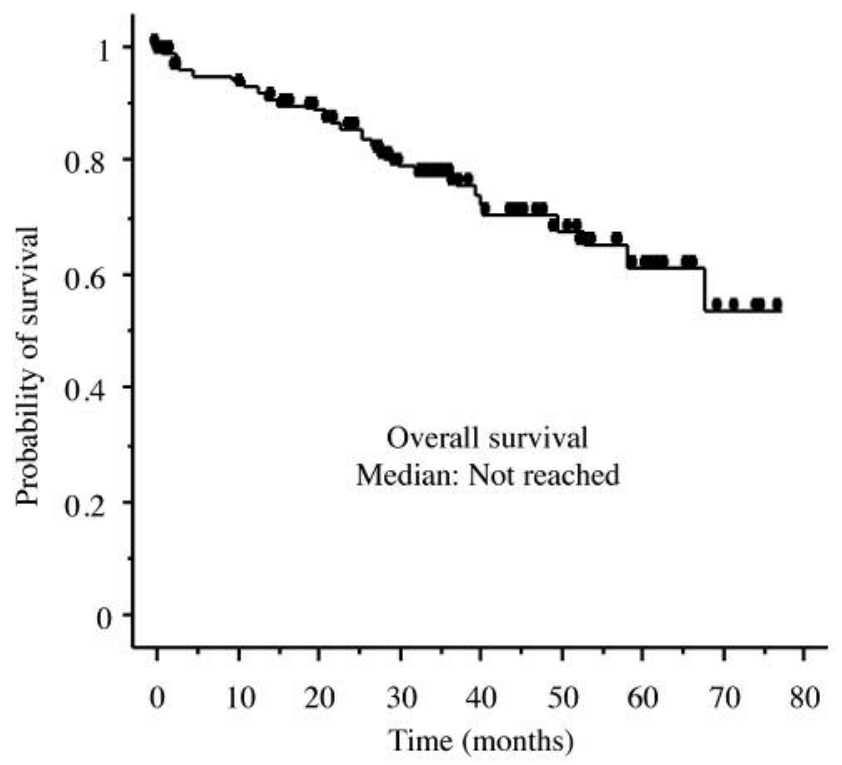

Figure 1. Survival curves in patients with pulmonary metastasis. A: Disease-free survival and B: overall survival after surgery.

Table II. Prognostic factors for survival.

\begin{tabular}{|c|c|c|c|c|}
\hline \multirow[b]{2}{*}{ Factor (n) } & \multicolumn{2}{|c|}{ Univariate } & \multicolumn{2}{|c|}{ Multivariate } \\
\hline & HR $(95 \% \mathrm{CI})$ & $p$-Value & $\mathrm{HR}(95 \% \mathrm{CI})$ & $p$-Value \\
\hline \multicolumn{5}{|l|}{ Gender } \\
\hline Female $(n=48)$ & 1 & & 1 & \\
\hline Male $(n=58)$ & $1.8(0.40-2.20)$ & 0.13 & $2.5(1.05-6.01)$ & 0.04 \\
\hline \multicolumn{5}{|l|}{ Size of PM } \\
\hline$\leq 3 \mathrm{~cm}(\mathrm{n}=93)$ & 1 & & 1 & \\
\hline$>3 \mathrm{~cm}(\mathrm{n}=13)$ & $1.1(0.30-3.26)$ & 0.97 & $1.2(0.33-4.54)$ & 0.75 \\
\hline \multicolumn{5}{|l|}{ Number of PMs } \\
\hline Single $(n=78)$ & 1 & & 1 & \\
\hline Multiple $(\mathrm{n}=28)$ & $1.3(0.58-2.43)$ & 0.54 & $1.2(0.42-4.63)$ & 0.59 \\
\hline \multicolumn{5}{|l|}{ Site of PM } \\
\hline Unilateral $(\mathrm{n}=87)$ & 1 & & 1 & \\
\hline Bilateral $(n=19)$ & $1.4(0.58-1.09)$ & 0.47 & $1.3(0.34-4.70)$ & 0.72 \\
\hline \multicolumn{5}{|l|}{ Surgical procedure } \\
\hline Partial $(n=70)$ & 1 & & 1 & \\
\hline Segmentectomy or Lobectomy $(n=36)$ & $0.9(0.41-2.02)$ & 0.82 & $1.4(0.57-3.46)$ & 0.46 \\
\hline \multicolumn{5}{|l|}{ Primary organ } \\
\hline Colorectal $(n=43)$ & 1 & & 1 & \\
\hline Except colorectal $(n=63)$ & $3.8(1.47-10.3)$ & $0.006 *$ & $4.6(1.69-12.56)$ & $0.003 *$ \\
\hline \multicolumn{5}{|l|}{ Time to MT from primary operation } \\
\hline$>36$ months $(\mathrm{n}=49)$ & 1 & & 1 & \\
\hline$<36$ months $(\mathrm{n}=57)$ & $1.3(0.61-2.78)$ & 0.48 & $1.2(0.54-2.53)$ & 0.70 \\
\hline \multicolumn{5}{|l|}{ Chemotherapy after MT } \\
\hline Yes $(n=38)$ & 1 & & 1 & \\
\hline No $(n=68)$ & $1.2(0.55-2.59)$ & 0.65 & $1.2(0.52-2.56)$ & 0.71 \\
\hline
\end{tabular}

CI: Confidence interval; PM: pulmonary metastasis; MT: metastasectomy. 


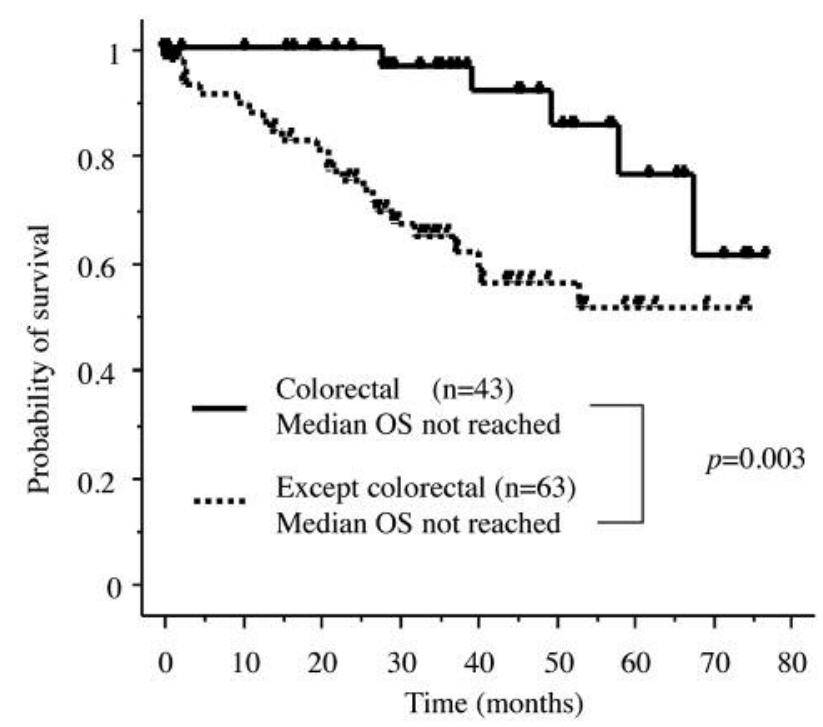

Figure 2. Overall survival curves in patients with pulmonary metastasis from colorectal carcinoma and other sites.

\section{Discussion}

The development and advancement of systemic chemotherapy have improved the outcomes of many metastatic MST patients. The median OS of patients who received systemic chemotherapy was previously determined to be 11.7 months in metastatic colorectal carcinoma (13). Recently, however, that median OS has been prolonged to about 30 months with advances in systemic chemotherapy $(14,15)$. Furthermore, while not as much as with colorectal carcinoma, the prolongation of OS has also been observed in other MSTs with the progress of chemotherapy.

Pulmonary metastasis is actually a hematogenous metastasis (16). Therefore, the appropriate route of management is generally systemic chemotherapy. However, several retrospective studies have reported the effectiveness of metastasectomy for PMs in certain MSTs (4, 11, 17-20). Furthermore, the long-term results of lung metastasectomy have shown it to be a safe and potentially curative procedure (4). Indeed, several retrospective studies in patients with PMs from colorectal carcinoma reported the effectiveness of metastasectomy for PMs $(5,6,8)$. The prognostic factors of MT were found to include the tumor marker level (e.g. carcinoembryonic antigen [CEA] levels in colorectal carcinoma), the number of PMs, an extrathoracic metastatic lesion, and the disease-free interval. However, the definitive prognostic factors of MT are still unclear, and the most useful factor may not be able to be evaluated until after MT and longterm follow-up.
Table III. Hazard ratio by primary organ.

\begin{tabular}{lcc}
\hline Factor $(\mathrm{n})$ & HR & 95\%CI \\
\hline Primary organ & & \\
Colorectal carcinoma $(\mathrm{n}=43)$ & 1 & $0.11-8.40$ \\
Esophageal/gastric $(\mathrm{n}=10)$ & 1.9 & $0.17-20.6$ \\
Gynecologic $(\mathrm{n}=8)$ & 2.7 & $0.28-26.3$ \\
Breast $(\mathrm{n}=6)$ & 3.0 & $0.26-33.8$ \\
Head and neck $(\mathrm{n}=10)$ & 3.2 & $0.32-40.0$ \\
Soft tissue sarcoma $(\mathrm{n}=14)$ & 3.5 & $0.42-29.4$ \\
Hepatocellular carcinoma $(\mathrm{n}=3)$ & 8.3 & $0.72-90.3$ \\
Urinary tract $(\mathrm{n}=12)$ & 8.9 & $1.10-72.9$ \\
\hline
\end{tabular}

HR: Hazard ratio; CI: confidential interval.

In this study, we evaluated the appropriateness of MT, with a focus on the primary organ. The multivariate analysis showed that colorectal carcinoma cases would benefit the most from resection. Although several studies have reported a better survival of patients with a long interval from primary therapy, including operation, such patients showed no significant improvement over those with a short interval in this study.

A number of advances have been made in surgical techniques in recent years. Most pulmonary metastasectomies are performed by video-assisted thoracoscopic surgery (VATS), as partial resection is performed in MT. Several studies have reported that VATS is the preferable approach due to its superior functional outcome over thoracotomy in MT (21). Therefore, MT might be an even safer procedure than before.

Importantly, pulmonary mastectomy may not only play a role in improving the survival but may also be considered for palliative reasons. Although the observed cases were not colorectal carcinoma ones, a phase II study examined the role of pulmonary mastectomy on the quality of life in patients with diseases not amenable to chemotherapy (22). That study showed that MT in patients with PMs favorably influenced the quality of life in symptomatic patients, although there was a risk of worsening the quality of life in asymptomatic patients without any survival advantage.

Molecular-targeted drugs and immune-checkpoint inhibitors are being developed at present, and they are helping to improve the prognosis of several carcinomas. For these therapies, the detection of driver mutations and programmed cell-death ligand 1 (PD-L1) expression are necessary. In cases in which MT cannot directly prolong the survival of patients, the surgery may still facilitate the selection of more effective therapies. With advances in surgical technology (e.g. VATS), the patient burden should ease even further. Although such discussion is considered to fall outside the scope of this study, pathological diagnosis and genetic testing (e.g. KRAS mutation of colorectal carcinoma) becomes possible by performing MT. 
Several limitations associated with the present study warrant mentioning. First, the study was retrospective and non-randomized in nature and was conducted at a single institution. Second, the sample size was small. Finally, the therapy after MT was not sufficiently considered.

In conclusion, we evaluated the appropriateness of MT, with a focus on the primary organ. Although it could not simply be compared because MST has a different survival, colorectal carcinoma was associated with a more survival benefit than caracinoma of other primary organs. Due to this survival benefit, colorectal carcinoma cases should be more aggressively considered for MT than other primary organ cases.

\section{References}

1 Kim JY, Park IJ, Kim HR, Kim DK, Lee JL, Yoon YS, Kim CW, Lim SB, Lee JB, Yu CS and Kim JC: Post-pulmonary metastasectomy prognosis after curative resection for colorectal cancer. Oncotarget 8: 36566-36577, 2017.

2 Inoue $\mathrm{M}$, Ohta $\mathrm{M}$, Iuchi $\mathrm{K}$, Matsumura $\mathrm{A}$, Ideguchi $\mathrm{K}$, Yasumitsu T, Nakagawa K, Fukuhara K, Maeda H, Takeda S, Minami M, Ohno Y and Matsuda H: Benefits of surgery for patients with pulmonary metastases from colorectal carcinoma. Ann Thorac Surg 78: 238-244, 2004.

3 Onaitis MW, Petersen RP, Haney JC, Saltz L, Park B, Flores R, Rizk N, Bains MS, Dycoco J, D'Amico TA, Harpole DH, Kemeny N, Rusch VW and Downey R: Prognostic factors for recurrence after pulmonary resection of colorectal cancer metastases. Ann Thorac Surg 87: 1684-1688, 2009.

4 Pastorino U, Buyse M, Friedel G, Ginsberg RJ, Girard P, Goldstraw P, Johnston M, McCormack P, Pass H and Putnam JB, Jr.: Long-term results of lung metastasectomy: prognostic analyses based on 5206 cases. J Thorac Cardiovasc Surg 113: 37-49, 1997.

5 Hirosawa T, Itabashi M, Ohnuki T, Yamaguchi N, Sugihara K and Kameoka S: Prognostic factors in patients undergoing complete resection of pulmonary metastases of colorectal cancer: a multi-institutional cumulative follow-up study. Surg Today 43: 494-499, 2013.

6 Watanabe K, Nagai K, Kobayashi A, Sugito M and Saito N: Factors influencing survival after complete resection of pulmonary metastases from colorectal cancer. Br J Surg 96: 1058-1065, 2009.

7 Gonzalez M, Poncet A, Combescure C, Robert J, Ris HB and Gervaz P: Risk factors for survival after lung metastasectomy in colorectal cancer patients: a systematic review and metaanalysis. Ann Surg Oncol 20: 572-579, 2013.

8 Iizasa T, Suzuki M, Yoshida S, Motohashi S, Yasufuku K, Iyoda A, Shibuya K, Hiroshima K, Nakatani Y and Fujisawa T: Prediction of prognosis and surgical indications for pulmonary metastasectomy from colorectal cancer. Ann Thorac Surg 82: 254-260, 2006.

9 Osoegawa A, Kometani T, Fukuyama S, Hirai F, Seto T, Sugio $\mathrm{K}$ and Ichinose $\mathrm{Y}$ : Prognostic Factors for Survival after Resection of Pulmonary Metastases from Colorectal Carcinoma. Ann Thorac Cardiovasc Surg 22: 6-11, 2016.

10 Belal A, Salah E, Hajjar W, El-Foudeh M, Memon M, Ezzat A and Al-Kattan K: Pulmonary metastatectomy for soft tissue sarcomas: is it valuable? J Cardiovasc Surg (Torino) 42: 835$840,2001$.
11 Iijima Y, Akiyama H, Atari M, Fukuhara M, Nakajima Y, Kinosita $\mathrm{H}$ and Uramoto $\mathrm{H}$ : Pulmonary Resection for Metastatic Gastric Cancer. Ann Thorac Cardiovasc Surg 22: 230-236, 2016.

12 Zhao Y, Li J, Li C, Fan J and Liu L: Prognostic factors for overall survival after lung metastasectomy in renal cell cancer patients: A systematic review and meta-analysis. Int J Surg 41: 70-77, 2017.

13 Lumachi F, Chiara GB, Tozzoli R, Del Conte A and Basso SM: Factors Affecting Survival in Patients with Lung Metastases from Colorectal Cancer. A Short Meta-analysis. Anticancer Res 36: 13-19, 2016.

14 Loupakis F, Cremolini C, Masi G, Lonardi S, Zagonel V, Salvatore L, Cortesi E, Tomasello G, Ronzoni M, Spadi R, Zaniboni A, Tonini G, Buonadonna A, Amoroso D, Chiara S, Carlomagno C, Boni C, Allegrini G, Boni L and Falcone A: Initial therapy with FOLFOXIRI and bevacizumab for metastatic colorectal cancer. N Engl J Med 371: 1609-1618, 2014.

15 Yamazaki K, Nagase M, Tamagawa H, Ueda S, Tamura T, Murata K, Eguchi Nakajima T, Baba E, Tsuda M, Moriwaki T, Esaki T, Tsuji Y, Muro K, Taira K, Denda T, Funai S, Shinozaki K, Yamashita H, Sugimoto N, Okuno T, Nishina T, Umeki M, Kurimoto T, Takayama T, Tsuji A, Yoshida M, Hosokawa A, Shibata Y, Suyama K, Okabe M, Suzuki K, Seki N, Kawakami K, Sato M, Fujikawa K, Hirashima T, Shimura T, Taku K, Otsuji T, Tamura F, Shinozaki E, Nakashima K, Hara H, Tsushima T, Ando M, Morita S, Boku N and Hyodo I: Randomized phase III study of bevacizumab plus FOLFIRI and bevacizumab plus mFOLFOX6 as first-line treatment for patients with metastatic colorectal cancer (WJOG4407G). Ann Oncol 27: 1539-1546, 2016.

16 Mehlen P and Puisieux A: Metastasis: a question of life or death. Nat Rev Cancer 6: 449-458, 2006.

17 Aurello P, Petrucciani N, Giulitti D, Campanella L, D'Angelo F and Ramacciato G: Pulmonary metastases from gastric cancer: Is there any indication for lung metastasectomy? A systematic review. Med Oncol 33: 9, 2016.

18 Fan J, Chen D, Du H, Shen C and Che G: Prognostic factors for resection of isolated pulmonary metastases in breast cancer patients: a systematic review and meta-analysis. J Thorac Dis 7: 1441-1451, 2015.

19 Kanamori J, Aokage K, Hishida T, Yoshida J, Tsuboi M, Fujita $\mathrm{T}$, Nagino $\mathrm{M}$ and Daiko $\mathrm{H}$ : The role of pulmonary resection in tumors metastatic from esophageal carcinoma. Jpn J Clin Oncol 47: 25-31, 2017

20 Sponholz S, Schirren M, Kudelin N, Knochlein E and Schirren J: Results of Pulmonary Resection: Other Epithelial Malignancies. Thorac Surg Clin 26: 99-108, 2016.

21 Numan RC, Baas P, Klomp HM and Wouters MW: Optimal surgical management of pulmonary metastases: VATS versus thoracotomy. Respirology 21: 188-190, 2016.

22 Otto T, Krege S, Suhr J and Rubben H: Impact of surgical resection of bladder cancer metastases refractory to systemic therapy on performance score: a phase II trial. Urology 57: 55-59, 2001.

Received November 6, 2017

Revised December 3, 2017

Accepted December 4, 2017 